\title{
ACESSO À JUSTIÇA: REFORMA do ESTADO, NOVA ESFERA PÚBLICA E CONTROLE DO TRABALHO JUDICÁRIO
}

Access to justice: state reform, the new public sphere, and the judiciary control

\section{Jose Antonio Callegari}

Mestrando pela Universidade Federal Fluminense (Sociologia Jurídica).

Doutorando pela Universidad Nacional de Lomas de Zamora - Argentina (Derecho). Professor Conferencista da Escola Superior de Polícia Militar do Estado do Rio de Janeiro (Direito Constitucional e Administrativo).

E-mail: calegantonio@yahoo.com.br

\section{Marcelo Pereira De Mello}

Mestrado em Sociologia pela Sociedade Brasileira de Instrução - SBI/IUPERJ e doutorado em Ciência Política (Ciências Humanas) pela Sociedade Brasileira de Instrução - SBI/IUPERJ. É um dos fundadores do Programa de Pós Graduação em Sociologia e Direito (PPGSD) da Universidade Federal Fluminense (UFF).

E-mail:mpmello@unisys.com.br

RECEBIDO EM: 09.09.2012

Aprovado EM: 07.01.13

\section{RESUMO}

No contexto de acesso a Justiça, pretende-se comunicar algumas reflexões sobre o controle do trabalho no sistema judiciário, no qual são exercidas funções essenciais para a administração da Justiça. A prestação jurisdicional célere e eficiente requer um modelo de gestão processual dialógico concatenado com o seu tempo, onde os fluxos de informações devem estar abertos e disponíveis aos cidadãos. A efetividade da jurisdição, por suposto, requer a existência de mecanismos e canais que garantam a acessibilidade dos cidadãos como 
detentores do poder político, concernidos, pois, na esfera pública brasileira. Temas como tecnologia, administração, gestão, transparência, seleção e controle serão analisados no decorrer do artigo. Através de análise documental e bibliográfica, pretendemos apresentar alguns aspectos da nova esfera pública judiciária, no contexto das Reformas do Estado, ocorridas nas últimas décadas. Neste sentido, destaca-se a atuação do Conselho Nacional de Justiça e das ouvidorias judiciárias como instrumentos de controle do trabalho judiciário e garantidores do acesso do cidadão a este subsistema social, não somente como consumidor dos serviços prestados, mas como gestor participativo do modelo gerencial proposto com as reformas implementadas através das EC 19/98 e 45/04. Pretende-se, com isto, propor reflexões sobre o modelo quantitativo de controle da produção judiciária sem olvidar que o processo é um instrumento de garantia de direitos fundamentais da pessoa humana. Assim, políticas públicas de controle e gestão quantitativa não podem se afastar do conteúdo moral que deve reger a vida de relação. Estratégias instrumentais comprometem a concretização dos direitos humanos cuja função última é dignificar a pessoa em sua existência como um fim em si mesma.

Palavras-chave: Reformas. Nova esfera pública. Controle do TRABALHO JUDICIÁRIO.

\section{Abstract}

In the context of access to justice, it is intended to communicate some thoughts on the work control in the judiciary, in which core functions are exercised in the administration of justice. A speedy and efficient adjudication requires a dialogical process management model concatenated with your time, where information flows must be open and available to citizens. The effectiveness of the jurisdiction, of course, requires the existence of mechanisms and channels that ensure accessibility for citizens and holders of political power, concerned because in the Brazilian public sphere. Topics such as technology, management, governance, transparency, choice and control will be analyzed throughout the article. Through document analysis and literature review, we intend to present some aspects of the new public sphere judicial reforms in the context of the state, occurred in recent decades. In this sense, there is the role of the National Council of Justice and judicial ombudsman as instruments of labor control judiciary and guaranteeing citizen access to this social subsystem, not only as a consumer of services, but as manager of participatory management model with proposed reforms implemented through the EC 19/98 and 45/04. It is intended with this, offer reflections on the quantitative model to control 
production without forgetting that the judicial process is a means of ensuring fundamental human rights. Thus, public policy and management quantitative control can not be away from the moral content that should govern the life of the relationship. Strategies instrumental undertake the realization of human rights whose ultimate function is to dignify the person in your life as an end in itself.

Keywords: Reforms. New Public Sphere. Control of the JUdiciary

Sumário: Introdução. 1. Reforma do Estado e nova esfera pública judiciária. 2. Gestão pública participativa. 3. Conselho Nacional de Justiça e gestão estratégica. 4. Ouvidoria judiciária. 5. Controle externo do trabalho judiciário. Conclusão. Referências.

\section{INTRODUÇÃO}

A judicialização das relações de trabalho ultrapassou os limites da relação de emprego normatizada na CLT e legislação extravagante. Neste sentido, o estudo amplo das relações de trabalho sugere incursões também no trabalho organizado no setor público. Diante da mudança estrutural da esfera pública judiciária (HABERMAS, 2003), constata-se que o trabalho neste subsistema social vem sofrendo progressivas transformações, tais como: implementação do processo judicial eletrônico; supressão e otimização de rotinas nos órgãos judiciários; formação e aperfeiçoamento continuado de seus quadros; aumento da intensidade do trabalho e surgimento de questões éticas e de saúde quanto aos efeitos concretos do modelo de gestão quantitativa adotado no setor público.

As teorias e estratégias adotadas verticalmente pelo alto escalão do Poder Judiciário materializam-se em forma de trabalhos prescritos que nem sempre são executados como planejados porque entre o prescrito e o real existe um hiato correspondente à história de vida de cada ator, cultura das organizações e local onde as normas nacionalmente padronizadas devem ser executadas. Sem contar que processos de mudanças demandam tempo e, por vezes, resistências legítimas como é o caso da que ocorre em relação à progressiva redução do poder judicial na direção do processo.

Neste contexto, pretende-se abordar o trabalho das ouvidorias judiciárias como importante canal de acesso dos cidadãos e mecanismo de controle institucional do trabalho judiciário. Este canal de comunicação, 
concebido ora como abertura cognitiva, que permite a seleção de irritações do meio da vida, ora como espaço público legitimado para o exercício da cidadania ativa, recebe manifestações dos usuários apresentados por diversas formas: carta, e-mail, telefone, pessoalmente, etc. No aspecto comunicacional, a leitura dos mapas estatísticos produzidos pelas ouvidorias, por exemplo, pode fornecer um sentido (organicidade) para o trabalho judiciário permitindo a elaboração de estratégias que ampliem a eficiência de seus órgãos internos e reduzam contradições performáticas entre atos e fala que podem desestabilizar a relação entre o Poder Judiciário e os consumidores dos serviços prestados. O que se pretende é abordar o campo empírico de atuação das ouvidorias para extrair das observações elementos que permitam avaliar o grau de participação dos indivíduos no controle externo do trabalho desenvolvido e sua inclusão social nos debates contemporâneos a respeito da reconfiguração da esfera pública judiciária.

\section{REForma do Estado e nOVA ESFERA PÚBLICA JUdiCIÁRIA}

A respeito da reconfiguração na esfera pública judiciária, faz-se necessário contextualizar o tema na dinâmica das reformas do Estado ocorridas principalmente nas décadas de 80 e 90. Num cenário global, repleto de desafios típicos de sociedades complexas (GIDDENS, 1991), é comum observarmos mudanças constantes na esfera pública (HABERMAS, 2003) na forma de reorganizações políticas, econômicas, administrativas e sociais. O processo de globalização, por suposto, deve ser analisado dentro de um contexto amplo e complexo. Certamente, não é um fenômeno econômico isolado de outras causalidades, tais como: política, cultura e níveis diferenciados de desenvolvimento presentes nos Estados nacionais. Desta forma, os impactos decorrentes da globalização não devem significar pura e simplesmente o desmantelamento da máquina administrativa estatal (CARDOSO, in BRESSER PEREIRA E SPINK: 2006, p. 15). As mudanças que se iniciaram naquelas décadas refletiam, para seus idealizadores, o abandono de posições refratárias e estagnadas historicamente como ocorreu na América latina e particularmente no Brasil.

Diante de uma constituição rígida do tipo analítica, as reformas estruturais do modelo administrativo estatal demandaram discussão e aprovação de Emendas Constitucionais, destacando-se as de n 19/98 e 45/04. A nova configuração administrativa adotada propunha efetivar os seguintes princípios constitucionais: legalidade, impessoalidade, moralidade, publicidade e eficiência. A respeito do paradigma da gestão pública participativa, foram criados os seguintes mecanismos de acesso do usuário: reclamação, assegurada a manutenção de serviços de atendimento e avaliação periódica da qualidade de 
serviços (externa e interna); acesso a registros administrativos e a informações sobre atos de governo e representação contra o exercício negligente ou abusivo de cargo, emprego ou função.

O recém-inaugurado Estado Democrático de Direito acendeu o espírito de cidadania cerceado em anos de regimes autoritários. Logo a Administração Pública viu-se compelida a atender os usuários na dupla qualidade de consumidores de serviços estatais e cidadãos detentores da soberania popular, abrindo-se cognitivamente para as demandas crescentes por inclusão social e participação no jogo político democrático. Então, o modelo gerencial mostrouse, aparentemente, adequado para viabilizar a governança da coisa pública segundo os 03 (três) E: eficiência, efetividade e eficácia.

Neste processo de aproximação e aprimoramento das funções estatais, a sociedade deveria aprender também a dialogar com o Estado, sugerindo-se o seguinte:

"[...] nós temos que preparar a nossa administração para a superação dos modelos burocráticos do passado, de forma a incorporar técnicas gerenciais que introduzam na cultura do trabalho público as noções indispensáveis de qualidade, produtividade, resultados, responsabilidade dos funcionários, entre outras" (CARDOSO, in BRESSER PEREIRA: 2009).

Percebe-se, com isto, um movimento de transição complexo que requer a participação de todos segundo o modelo de ação comunicativa atuante na esfera pública através da formação de consensos ou superação de dissensos mediados pelo Direito (HABERMAS, 2003).

Tratando da gestão no setor público, Bresser Pereira (2009) apresenta argumentos sobre estratégia de formatação de um novo Estado. Na década de 80 , por exemplo, havia um cenário político propício para ajustes estruturais na esfera pública. Ele entende que "a questão central hoje é como reconstruir o Estado". O autor, ex-ministro encarregado da reforma administrativa levada a cabo, diz que naquela década houve uma forte crise de governabilidade vinculada a questões fiscais, excesso de intervenção estatal e ineficiência da burocracia. Em sua análise, a reforma administrativa envolveu aspectos políticos, econômicos e administrativos. No primeiro caso, estaria em jogo a promoção da governabilidade. Nos aspectos econômicos e administrativos, a preocupação estava em aumentar a capacidade de governar. Para ele, igualmente importante é tornar o serviço público mais coerente com o capitalismo contemporâneo, permitindo o acesso do usuário a mecanismos de participação e controle da Administração Pública. Em sua leitura, vem aumentando a consciência crítica dos cidadãos para exigir tal coerência e efetividade dos gestores públicos. A 
relação entre oferta e procura, no diálogo que se estabelece entre cidadão e Estado, impõe constante aperfeiçoamento da esfera pública estatal para atender a demandas sociais reprimidas por anos de ineficiência administrativa.

Nas palavras de Bresser Pereira (2009), o modelo gerencial orientase para os resultados, na busca da eficiência administrativa. Este modelo de gestão requer instrumentos adequados para funcionamento eficiente, tais como: descentralização, delegação de autoridade e responsabilidade do gestor público ou prestação de contas (accountability), bem como rígido controle do seu desempenho.

\section{GeStão pública PARTicipativa}

A nova esfera pública brasileira está comprometida formalmente, ao menos, com a efetividade dos direitos humanos. Neste sentido, cabe ao Estado garantir o exercício dos direitos sociais e individuais; a liberdade; a segurança; o bem-estar; o desenvolvimento; a igualdade e a justiça como valores supremos de uma sociedade fraterna, pluralista e sem preconceitos. Logicamente, a concretização deles requer participação efetiva dos cidadãos como construtores da esfera pública participativa.

Por suposto, o exercício de direitos e a defesa de garantias fundamentais da pessoa humana requerem ações comunicativas voltadas para o bem estar coletivo através de procedimentos deliberativos que permitam aos cidadãos realizarem-se na vida comunitária. Desta forma, o Estado detém o poder-dever de consolidar objetivos fundamentais para realização plena da pessoa humana, tais como: a construção de uma sociedade livre, justa e solidária; a garantia do desenvolvimento nacional; a erradicação da pobreza e da marginalização, bem como a redução das desigualdades sociais e regionais; a promoção do bem de todos, sem preconceitos de origem, raça, sexo, cor, idade e quaisquer outras formas de discriminação. Percebe-se, com isto, que a esfera pública brasileira vem sofrendo mudanças ideológicas, através da constitucionalização de princípios de proteção da pessoa humana. Aparentemente, o Estado vem adotando um modelo gerencial discursivo para superação de dissensos e ampliação do acesso dos cidadãos aos serviços públicos.

A respeito do modelo gerencial participativo, veja-se que o artigo $5^{\circ}$ da Constituição garante ao cidadão a livre manifestação do pensamento, o direito de resposta, o acesso à informação, a defesa do consumidor, o direito de receber informações dos órgãos públicos e o direito de petição. Este novo perfil do Estado consolidou-se com a edição da Emenda Constitucional n ${ }^{\circ}$ 19/98 que tratou da reforma da Administração Pública. Logo no caput do artigo 37 da Constituição Federal, foi inserido o princípio da eficiência como requisito 
para implantação de melhorias na gestão pública. Com este propósito, o $\S 3^{\circ}$ acrescenta ao texto constitucional o seguinte dispositivo: "A lei disciplinará as formas de participação do usuário na administração pública direta e indireta...". Esta participação nada mais é do que um modo de exercício da cidadania diante da abertura sistêmica garantida pela nova estrutura da esfera pública brasileira. Uma das formas de participação do usuário ocorre com a apresentação de reclamações relativas à prestação de serviços públicos em geral, onde podemos incluir os serviços judiciários. Nestes termos, fica assegurada ao usuário a manutenção de serviços de atendimento e avaliação periódica, externa e interna, da qualidade dos serviços. Aqui encontramos o embrião para a criação das ouvidorias judiciárias no Brasil. Também foi garantido o acesso a registros administrativos e informações sobre atos de governo, observando-se questões de sigilo de Estado.

Diante deste leque amplo de garantias fundamentais da pessoa humana e abertura cognitiva dialógica, o Poder Judiciário viu-se diante da necessidade de modernizar sua estrutura funcional como organização submetida aos paradigmas da gestão pública participativa. Por conta disto, as palavras correntes na administração judiciária são: planejamento estratégico, metas e resultados. O foco da atuação judiciária, pois, deslocou-se significativamente. Não basta mais atentar para a sua atividade-fim (jurisdição). Há que estabelecer mecanismos eficientes de gestão e controle de sua atividade principal. Logo, sua atividade-meio (administração) ganha um significado muito importante para consolidação do modelo gerencial no setor público. Este modelo de gestão concentra sua atenção também no ritmo do trabalho desenvolvido na "linha de produção", onde fatores "mercadológicos", tais como tempo e demanda, geram situações contraditórias do tipo: quantidade $\mathrm{X}$ qualidade ou segurança jurídica $\mathrm{X}$ celeridade. A propósito, quando se fala em controle de produção do trabalho judiciário objetiva-se atender aos interesses dos jurisdicionados segundo as várias dimensões da cidadania: política, econômica e social. Politicamente, o cidadão é considerado como participante da esfera pública, uma vez que detém parcela do poder materializado na configuração institucional do Estado. Sob o aspecto econômico, ele é considerado um consumidor de serviços prestados ou postos à sua disposição. Na dimensão social, ele participa de um jogo dialético entre expectativas de interesses, devendo prevalecer atitudes de entendimento em função do bem comum. Este modelo de gestão permite ao cidadão participar do controle das atividades do Estado, como já foi dito antes.

No caso particular do Poder Judiciário, a demanda por inclusão social e gestão pública participativa levou à edição da Emenda Constitucional $n^{\circ}$ 45/04, com ela surgindo o Conselho Nacional de Justiça como órgão central do "sistema" judiciário. Este Conselho detém competência constitucional para 
estabelecer políticas de modernização da gestão do trabalho judiciário como será analisado adiante.

\section{Conselho Nacional de Justiça e gestão estratégica}

Incumbe ao Conselho Nacional de Justiça o controle das atividades desenvolvidas pelo Poder Judiciário em nível nacional. Orienta sua atuação pelos princípios da eficiência e transparência administrativa e processual. Através de planejamento, procura aperfeiçoar os serviços prestados aos cidadãos. Tem como missão contribuir para que a prestação jurisdicional seja realizada de acordo com os princípios da moralidade, eficiência e efetividade. Em sua visão institucional, atua como instrumento efetivo de desenvolvimento do Poder Judiciário. Para alcançar os seus objetivos adota as seguintes diretrizes: planejamento estratégico e proposição de políticas judiciárias; modernização tecnológica do Judiciário; ampliação do acesso à justiça, pacificação e responsabilidade social, bem como garantia do efetivo respeito às liberdades públicas e execuções penais.

Segundo o modelo gerencial adotado pelo Conselho Nacional de Justiça, foram estabelecidas, a partir de 2009, metas de nivelamento do Poder Judiciário, destacando-se na época a Meta 2 (identificação e julgamento de processos mais antigos distribuídos até 31.12.2005). Com a Meta 2, o Poder Judiciário começou a se alinhar com os princípios constitucionais da eficiência, efetividade e razoável duração do processo. A preocupação manifesta era acabar com o estoque de processos causadores de altas taxas de congestionamento nos tribunais. A respeito do estoque de processos, é sugestiva a observação de que é necessário haver fixação de um número mínimo de juízes de primeira instância em função do número de habitantes e de uma correspondente proporção mínima de magistrados dos tribunais de segunda instância para que a prestação jurisdicional seja tratada como a mais nobre atividade-fim do Estado, não podendo, em hipótese alguma, subordinar-se à regra instrumental de balanceamento das contas públicas. Não se pode esquecer que nos processos flamam dramas existenciais da pessoa humana. Pensá-los como causa do congestionamento judiciário é adotar suspeitoso cálculo instrumental que vilipendia os mais basilares direitos fundamentais dos jurisdicionados quando coisificados em forma de simples dados estatísticos.

Prosseguindo com a análise, o CNJ adotou outras metas para organizar o trabalho nas varas judiciais, informatizar o Judiciário e proporcionar mais transparência quanto aos serviços prestados. A cada ano, vem adotando metas mais audaciosas, tendo como foco o aumento da agilidade e eficiência da Justiça. Em sua página na Internet, sugere que 
os tribunais deveriam dar conta de julgar todos os processos distribuídos até 31-12-2006. O que se observa, pois, é uma forte preocupação com o volume de trabalho produzido, sem haver um equacionamento preciso entre a exigência de produção quantitativa e a produção qualitativa focada na distribuição de justiça, segundo as características e complexidades das questões materiais envolvidas em cada processo. A neutralidade objetivante da gestão administrativa parece chocar-se com questões de ordem moral a respeito das formas de se fazer justiça. Olvidar questões morais relevantes implica coisificar a relação processual e, por decorrência, a dignidade da pessoa humana envolvida em lides judicializadas. Surge então um cenário que preocupa: a possibilidade de adoção de paradigmas utilitaristas de gestão focada no êxito da instituição, maximizando o alcance de metas institucionais e minimizando a questão moral que envolve a distribuição de justiça. No ano de 2011, por exemplo, foram selecionadas 04 metas para todo o Judiciário e metas específicas para cada segmento de Justiça (Trabalhista, Federal, Militar e Eleitoral), com exceção da Justiça Estadual. Pela primeira vez, observa-se certa abordagem de natureza qualitativa sinalizando talvez para a evolução do sistema de controle e estabelecimento de metas institucionais. Dentre as metas prescritas, uma guarda pertinência temática com o estudo proposto. A meta 04 de 2011 prevê a implantação de pelo menos um programa de esclarecimento ao público sobre as funções, atividades e órgãos do Poder Judiciário em escolas ou quaisquer espaços públicos. A proposta alinhase com os objetivos institucionais das ouvidorias como será apontado nos tópicos seguintes.

De toda sorte, o foco central das metas institucionais está direcionado para o julgamento quantitativo de processos e aprimoramento de mecanismos de gestão de pessoas. Aparentemente, prevalece o sistema de avaliação quantitativa da eficiência judiciária, sem que aspectos intrínsecos de cada tipo de relação material discutida em juízo sejam explicitamente considerados, não como obstáculo à celeridade processual e sim como elementos indispensáveis para um julgamento subjetivamente justo. $\mathrm{O}$ quadro mostra-se preocupante porque nos remete a questões de moralidade e de ética profissional em atividade cujos princípios da independência e imparcialidade funcionam como garantias da própria magistratura e dos jurisdicionados. O risco de domesticação dos subsistemas sociais pelo modelo gerencial quantitativo deve ser considerado com seriedade porque violenta a ordem democrática fundamentada na dignidade da pessoa humana. 


\section{OUVIDORIA JUDICIÁRIA}

Segundo o CNJ, a ouvidoria é a unidade responsável pelo Serviço de Atendimento ao Cidadão (SAC), conforme estabelece a Lei 12.527 de 2011, conhecida como Lei de Acesso à Informação. Note-se que o SAC do CNJ não se confunde com o SAC conhecido nas empresas privadas. O SAC presente nas empresas privadas é o Serviço de Atendimento ao Consumidor, que não deixa de ser um cidadão. A proteção ao consumidor, na verdade, é um dos embriões da ouvidoria no Brasil, vez que ela foi institucionalizada entre nós a partir da figura do Ombudsman que, em tradução livre, significa ouvidor-geral. O conceito tem origem na Suécia (1713), oficializando-se naquele país através da reforma constitucional de 1809. Era um funcionário nomeado pelo governo para ouvir as queixas dos cidadãos contra os maus serviços prestados e desvios de conduta dos funcionários públicos. Tinha status ministerial e atuava em várias linhas temáticas, tais como: discriminações étnicas, desvios de condutas de parlamentares, defesa dos consumidores, oferecimento de oportunidades iguais, atuação da imprensa, etc. No Brasil, ele foi introduzido através da reforma editorial no jornal paulistano Folha de S. Paulo na década de 80 . No caso brasileiro, já tivemos a figura do ouvidor no regime colonial. No entanto, pouco tinha a ver com o ouvidor contemporâneo. Aquele ouvidor colonial tinha função judicante e correcional, atribuições que hoje em dia não lhe cabem mais.

O modelo de ouvidoria adotado pelo CNJ tem o escopo de prestar serviço de informações ao cidadão sobre tramitação de documentos, além de protocolar requerimento de acesso à informação; além de outras atribuições tais como: orientar, transmitir informações e colaborar no aprimoramento das atividades desenvolvidas pelo Conselho, bem como promover a interação com os demais órgãos do Poder Judiciário para o atendimento às demandas recebidas e aperfeiçoamento dos serviços prestados.

Ela é um canal de acesso ao subsistema judiciário e, por conseguinte, também possui os seus mecanismos de acesso. Quer dizer, para entrar em contato com a ouvidoria do CNJ o cidadão dispõe de: formulário eletrônico, telefones e endereços para correspondência.

Dentro do modelo de gestão gerencial, a ouvidoria representa também um importante canal de controle do trabalho judiciário. Este controle tem dupla face. Internamente, é um canal de acesso dos servidores e magistrados que podem manifestar suas opiniões mantendo o sigilo de suas identidades, o que não se confunde com anonimato. $\mathrm{O}$ sigilo das manifestações é uma garantia da pessoa humana que por estar submetida a uma relação estatutária com o Estado não perde, por conta disto, suas prerrogativas civis. A outra face do controle é externa, pois qualquer cidadão pode acessar a ouvidoria para manifestar 
suas impressões sobre os serviços judiciários através de reclamações, elogios, denúncias, sugestões, críticas, etc.

\section{Controle eXterno do trabalho judiciáRio}

Particularmente, interessa agora examinar a ouvidoria no contexto do controle externo do trabalho judiciário. Sendo um órgão de controle juridicamente concebido, mostra-se pertinente trazer ao texto algumas reflexões de Alain Supiot. Para ele, existem duas concepções do Direito. A concepção transcendental ou jusnaturalista e a concepção positivista ou instrumental. No segundo caso, o direito seria pura técnica, neutra em si e vazia de sentido (SUPIOT, 2007). Utilizando a metáfora da carroça, diz que para alguns o direito seria um "meio capaz de transportar qualquer conteúdo normativo que seja, de sorte que tudo que é tecnicamente realizável deveria acabar sendo juridicamente permitido" (SUPIOT, 2007, p. 140). Aqui mora o perigo. Se o Direito é uma técnica desprovida de qualquer compromisso moral, como lidar com a questão do gerenciamento do trabalho judiciário através de prescrições normativas objetivantes que reduzem a capacidade de ação daqueles que executam este trabalho sob a perspectiva da distribuição de justiça?

Para ele, o objeto técnico se distingue do objeto natural porque seu sentido procede do homem que o modela e o utiliza (SUPIOT, 2007). Então, seria possível dizer que na utilização e modulação do objeto está presente o caráter ideológico da conduta humana presente também nas relações de trabalho? Sendo assim, modelos de gestão que prescrevem a precedência da quantidade sobre a qualidade não poderia incutir no homem uma racionalidade instrumental do tipo "farinha pouca, meu pirão primeiro"? Em outras palavras, diante do discurso objetivante para redução de estoques processuais não estaria o Poder Judiciário utilizando o Direito como objeto técnico, segundo cálculos estratégicos forjados em lógica instrumental? Qual o reflexo disto para o conteúdo moral de suas decisões?

Supondo, com o autor referenciado, que o homem dá sentido ao objeto técnico que utiliza é possível encontrar um alento diante do cenário objetivante imposto por esta forma de controle do trabalho judiciário. Para figurar a questão, imagine-se um revólver, uma faca e um tijolo nas mãos de um homicida. $\mathrm{O}$ sentido que ele confere aos três objetos será o mesmo: arma letal. Nas mãos de um fiscal em prova de natação, de um chef de cozinha e de um pedreiro, cada um destes objetos ganhará um significado próprio conforme a função que se lhes empregue. No caso do árbitro, um sinal de largada para os nadadores; para o chef de cozinha, um instrumento de arte no corte preciso dos ingredientes 
e para o pedreiro seria matéria prima do seu trabalho técnico. Seguindo esta suposição, imagine-se o processo nas mãos de funcionários do Estado que nele empreguem o sentido de garantia de direitos fundamentais e instrumento para distribuição de Justiça. Agora, tome-se o mesmo objeto nas mãos de quem adote postura objetivante: estoque que prejudica o êxito individual e da organização. Logicamente, o sentido empregado na utilização do objeto estará informado pela concepção de mundo que habita em cada qual. No caso em estudo, a concepção do próprio mundo do trabalho judiciário e sua finalidade precípua. A especulação que pode seguir a este exemplo não se restringe aos aspectos técnicos da gestão administrativa e processual. Pelo contrário, implicações de ordem moral e de justiça devem ser consideradas diante da necessidade de garantir a efetividade dos direitos fundamentais e a dignidade da pessoa humana como um fim em si mesma. Esta perspectiva sinaliza para a construção de espaços públicos que atendam aos imperativos da boa gestão pública sem olvidar que o Estado, não sendo um fim em si mesmo, é um meio para realização da pessoa humana como ser racional e dotado de dignidade (KANT, 2001).

O exemplo citado mostra como podem ser graves as repercussões sociais decorrentes do apego desmedido ao modelo de gestão gerencial. O risco da desqualificação do objeto (SUPIOT, 2007) é grave porque se pode perder a essência da função específica do Direito no universo das técnicas. Se o Direito é uma técnica dentre outras, não é uma técnica como as outras, lembra-nos Supiot. Para ele, o Direito permitiu tornar humanamente vivível a existência humana. A preocupação pela humanização da técnica deve orientar o pensamento reverso quanto à possibilidade da racionalização instrumental do uso deste objeto técnico. Num quadro de gestão gerencial objetivante, focado em produção quantitativa, o Direito seria utilizado como propulsor da humanização das tecnologias de informação e comunicação ou seria, ao contrário disto, um mecanismo que acentua ainda mais o caráter excludente do trabalho judiciário premido por metas de desempenho, lidando com o processo como um estoque a ser eliminado?

A função de controle do trabalho judiciário, que de alguma forma pode ser imputada à ouvidoria como mecanismo de gestão, está intimamente ligada aos modernos meios de comunicação e mesmo a procedimentos estabelecidos para veicular crescentes fluxos de informações. O controle de fluxo informacional atende ao objetivo de monitoramento estabelecido pelo sistema piramidal formatado pelo CNJ. Algo como um panóptico virtual de grande capilaridade e alcance.

Logicamente, a proceduralização elaborada pelo subsistema judiciário, com destaque para a produção quantitativa, não condiz com o modelo social inclusivo apresentado por Jürgen Habermas em sua Teoria da Ação 
Comunicativa. Isto porque, os procedimentos habermasianos não estariam informados por cálculos instrumentais voltados para o êxito próprio. $\mathrm{O}$ foco em metas de produção e desempenho pode transformar o processo em vilão. Ao invés de uma garantia da pessoa humana, seria mais um obstáculo a ser superado em nome da gestão processual estratégica e das "boas práticas" administrativas.

Supiot (2007), mais uma vez, adverte que não existe outra realidade tangível além daquela que se deixa ver por todos. Para ele, "as teorias da informação e da comunicação apreendem o ser humano apenas através da maneira pela qual ele se comunica com seu meio ambiente e reage aos sinais que dele recebe". Afirma que a natureza humana é ainda mais rica porque é rica de comunicações. Ora, a supressão da noção de espaço-tempo necessária para a cognição judicial no processamento, instrução e julgamento das lides implica em artificial subversão das coisas no mundo natural. A vida real, assim como o trabalho real, não obedece integralmente aos ritmos ditados pela vida e pelo trabalho prescrito. Logicamente, a prescrição a respeito da produção judiciária, através de regulações regulamentadas, não pode ser seguida à risca, sob pena de comprometimento das garantias fundamentais da pessoa humana e do próprio Estado Democrático de Direito.

Situado em uma sociedade de informação, também o Poder Judiciário tende a se adaptar a esta nova dinâmica social. O modelo de produção informacional (CASTELLS, 1999) produz um crescente aumento das obrigações (prestar informações e dever de transparência), afetando concepções tradicionais na relação profissional/consumidor e fornecedor/cliente. Ora, este modelo foi explicitamente adotado pela nova configuração da esfera pública judiciária. Já vimos que a Constituição Federal adotou os princípios da legalidade, imparcialidade, moralidade, publicidade, eficiência e transparência na gestão da coisa pública. Agregado a estes princípios, com a Emenda Constitucional 19/98, o paradigma da prestação de informações aos usuários foi constitucionalizado e, atualmente, normatizado através da Lei de Acesso à Informação.

De fato, a busca constante por mecanismos de regulação, que estabeleçam de alguma forma uma proximidade entre o prescrito e o real, entre o regulado e o vivido, tende a gerar uma superposição destes mecanismos com sérios riscos de aprisionamento burocrático naquilo que Weber denominou como "jaula de ferro" (2004). O controle do trabalho judiciário através de mecanismos informacionais, depende, por certo, da qualidade das comunicações estabelecidas entre o ambiente interno e o ambiente externo deste subsistema. Estas comunicações oferecem material de observação que, por sua vez, serão utilizados em processos seletivos que permitam reduções de complexidades e estabilização funcional sistêmica (LUHMANN, 2009). Desta forma, seguindo Supiot (2007), não há regulação sem regulador, seja na ordem da vida profissional ou na ordem da vida privada. 
Acrescente-se que a relação entre o computador e o seu utilizador nunca é uma relação binária. Ela opera sempre sob a égide do terceiro que inventou a máquina segundo seus interesses próprios (SUPIOT, 2007). Esta afirmação merece uma consideração. Quando o Poder Judiciário oferece um serviço de atendimento ao cidadão através da ouvidoria, é preciso analisar sob qual perspectiva ele é oferecido. Dentro de um sistema cada vez mais informatizado, caminhando a passos largos para a implementação integral do processo eletrônico, tanto o usuário interno do sistema quanto o consumidor dos serviços judiciários podem estar agindo conforme a racionalidade instrumental que elaborou os programas computacionais acessados por ambos. Desta forma, o empoderamento do cidadão seria tanto mais simbólico quanto mais sofisticado for o mecanismo de controle do terceiro, rompendo com isto a aparente relação binária entre prestador e consumidor deste serviço especializado.

Para o nosso autor, existe um fosso crescente separando o homem biológico e suas técnicas, que adquiriram um poder vertiginoso durante os últimos dois séculos, tornando-se uma ameaça para o homem, vez que posto a serviço dos seus instintos de predador, tal como ocorre na justificação dos discursos da livre concorrência, liberalização dos mercados e acirramento "saudável" da competitividade (SUPIOT, 2007). Em nosso contexto, a tirania da regulação técnica sobre a existência real do homem biológico tende a gerar descompassos prejudicais ao bom rendimento. Tarefas e atividades, metas e resultados são estabelecidos sem a devida consideração a respeito da multiplicidade de fatores que atuam na divisão social do trabalho. Logicamente, os sistemas de controle podem tiranizar ainda mais a existência do trabalhador que atua neste subsistema, seja ele juiz, servidor, advogado, promotor de justiça, defensor público, etc. Então as técnicas deixariam de ser humanamente suportáveis e, logicamente, a eficiência pretendida na prestação de serviço cada vez mais questionável.

O controle do trabalho judiciário, como qualquer tipo de controle desta natureza, pode implicar riscos. Um sério risco no trabalho informacional é o deslocamento espaço-temporal do trabalhador que se vê transportado para um mundo virtual em outro "tempo real". Surge, então, a fantasia da ubiqüidade (SUPIOT, 2007). A percepção simbólica do tempo-espaço vem desumanizando as relações de trabalho, uma vez que o tempo biológico do trabalhador é cada vez mais comprimido pelo tempo lógico do computador. Neste mundo virtual, perdem-se as referências de espaço e tempo (dia e noite). Nele, a jornada de trabalho é ditada pelo sistema e por sua necessidade de produção, produtividade, eficiência, transparência e resposta às expectativas dos consumidores. Por conseguinte, não há mais trabalhador que escape do seu tempo-ritmo (STANISLAVSK, 2009). Sendo assim, o trabalho intelectual, predominante 
no Poder Judiciário, converte-se em trabalho mensurável, domesticado através de procedimentos de controle e validação. Como dito, tanto faz o cargo ocupado (juiz ou servidor). O fato é que o trabalhador produz algo de alguma forma mensurável, cujo controle em tempo real já se faz presente através de um mecanismo de acompanhamento de sua produção. Este mecanismo adotado pelo CNJ chama-se processômetro. Funciona como um relógio digital no qual é lançado segundo a segundo, minuto a minuto, de hora em hora todo o tipo de tarefa desempenhada por Juízes de todos os graus de jurisdição. O processômetro é um tipo de observador interno (LUHMANN, 2009) que acompanha as operações, permitindo a seleção de disfunções sistêmicas a serem corrigidas na "linha de produção". A "esteira" deve rolar ininterruptamente. Acoplando o trabalhador judiciário ao computador, através de seu login, finalmente o sistema de gestão encontra um modo de controlar a sua produtividade, antes considerada imaterial ou intangível por causa da natureza intelectual de suas tarefas.

Neste cenário de observação e controle, típico de sociedades complexas, percebe-se o aumento de demandas por maior transparência e visibilidade. Há necessidade do corpo nu. Precisamos ver para crer. A expiação da autoridade confirma sua subordinação jurídica: o rei está nu. Não basta dizer que o subsistema judiciário é um sistema perito responsável por zelar pela legalidade e demais princípios constitucionais de garantia da pessoa humana. Não, claro que não! O próprio sistema perito requer que outro sistema perito venha controlar sua tendência hegemônica. Assim, a desconfiança tende a prevalecer e a boa conduta deve ser cotidianamente praticada e comprovada através da observação de um terceiro. Como na imagem de Borges (1972), o sistema perito pretende-se circular: Deus.

Não se supõe, ingenuamente, que o trabalho judiciário não deva ser submetido a nenhum tipo de controle quantitativo. Pelo contrário, o que se questiona é como se dá o controle do trabalho executado. Isto porque a questão de fundo está em confrontar o ideal democrático participativo, que supõe a inclusão de todos em um justo sistema de distribuição de justiça, em contraposição com um modelo tecnocrático inspirado em lógica instrumental, segundo a qual o Direito atuaria como técnica de dominação.

Neste contexto de controle total do trabalho, é que se procura questionar o papel das ouvidorias como mecanismo de gestão. Isto porque, ela atua também como filtro para seleção de irritações do meio ambiente (LUHMANN, 2009) com o propósito de viabilizar a estabilidade interna do sistema. 


\section{Controle Quantitativo do Trabalho Judiciário}

Vejamos, agora na prática, como se pode verificar a função de controle desempenhada pela ouvidoria judiciária. Observando-se $09^{\circ}$ relatório trimestral da ouvidoria do CNJ, período janeiro-março de 2012, vemos que foram recebidas no trimestre 5.732 demandas. O relatório do CNJ discrimina os canais de acesso utilizados pelos usuários na seguinte proporção: comunicação virtual $(96,39 \%)$, correio eletrônico $(1,88 \%)$, correspondência $(1,08 \%)$, ofício $(0,47 \%)$, ligações telefônicas $(0,16 \%)$ e atendimento presencial $(0,02 \%)$. A leitura que se extrai dos indicadores sugere que a comunicação virtual e por correio eletrônico predomina sobre formas de comunicação mais tradicionais. Em um primeiro momento se pode pensar que os números consolidam o processo de inclusão digital em andamento no Brasil. Os baixos índices de manifestações presencial, telefônica e por correspondência também podem ser atribuídos ao fato de a ouvidoria do CNJ funcionar em Brasília, dificultando a utilização destes canais de comunicação por quem reside longe da capital federal. Some-se a isto o custo elevado das ligações telefônicas pelo sistema de discagem à distância.

Outro ponto que merece destaque é a predominância, na ouvidoria do CNJ, de manifestações enviadas por servidores públicos, advogados e aposentados. A participação de cada um deles respectivamente é de 19,54\%, $16,56 \%$ e $11,60 \%$. A primeira leitura destes números sugere que se trata de um grupo com significativo senso crítico, aliado ao nível de escolaridade, perfil social e profissional. Por outro lado, os agentes públicos que atuam dentro do núcleo duro das funções de Estado são os que menos se manifestam, na seguinte proporção: militares $(2,13 \%)$, magistrado $(0,44 \%)$, membro do Ministério Público $(0,24 \%)$, delegado de polícia $(0,19 \%)$ e defensor público $(0,19 \%)$. Dado interessante: os presidiários representam 1,12\% das manifestações.

Segundo o CNJ, o maior nível de manifestação dos usuários diz respeito a reclamações em face da morosidade processual num total de 1.547 acessos. Bem próximos estão os números de acessos referentes à matéria jurisdicional, atuação do magistrado, decisão do $\mathrm{CNJ}$, decisão judicial, demanda fora da competência de sua competência, administração de tribunal, funcionamento/ procedimento de vara, girando em torno de 140 a 220 acessos.

A respeito da atuação da ouvidoria do CNJ foi apresentada aos usuários, no período analisado, pesquisa de opinião. Os itens avaliados foram: atendimento, tempo e clareza das respostas e desfecho da manifestação solicitada. 39,90\% manifestaram-se insatisfeitos e $60,10 \%$ disseram que estavam satisfeitos. O relatório notou que existe "certo grau de insatisfação, a indicar que a Ouvidoria precisa continuar a buscar o aprimoramento do seu trabalho". 
Nas considerações finais expostas no último relatório de 2012, o CNJ divulgou que os temas de maior incidência referem-se, em regra, aos serviços prestados pelo Poder Judiciário, como excesso de prazo na tramitação processual, o desempenho de magistrados, questões administrativas dos tribunais ou mesmo decisões judiciais. Há uma tendência de atuação integrada com ouvidorias dos tribunais em todo o Brasil, visando prestar atendimento às demandas recebidas e o permanente avanço nos serviços do Judiciário. Quando sua atuação não é cabível, a unidade procura indicar o órgão ou profissional a ser procurado pelo interessado.

Os elementos até aqui apresentados parecem confirmar a hipótese até aqui traçada. A ouvidoria também desempenha papel de controle do trabalho judiciário no que diz respeito ao trabalho prescrito, trabalho real e tarefas desempenhadas. O duplo papel desempenhado por ela não lhe retira o caráter de procedimento democrático de acesso aos serviços judiciários. Nesta quadra, a reflexão proposta teve o intuito de chamar a atenção para a possibilidade de haver um desvio de finalidade onde o direito de participação, natural num Estado Democrático, seja utilizado como mais uma técnica instrumental que reduz a função do Direito a rotinas burocráticas objetivantes que "inocentemente" e com "boas intenções" acabem por reduzir a dimensão do trabalho judiciário como fator de realização dos seus integrantes que prestam serviços essenciais à democracia.

\section{Conclusão}

Desenvolvemos até aqui alguns argumentos sobre a reforma do Estado e construção da nova esfera pública do Poder Judiciário. Neste sentido, foram analisados princípios constitucionais relativos à melhoria da gestão estatal. O modelo gerencial examinado aparentemente abre-se ao cidadão que passa a desempenhar o papel de observador do sistema, fornecendo manifestações utilizadas no aprimoramento deste subsistema social.

O Conselho Nacional de Justiça apresenta-se, pois, como o órgão central deste subsistema, destacando-se pela implementação de metas para aferição de resultados. Busca-se, com isto, aumentar o grau de controle do trabalho nele desenvolvido.

Por sua vez, as ouvidorias são sistematicamente institucionalizadas através do CNJ como local apropriado para que o sistema exerça uma comunicação ativa com os consumidores e também com os trabalhadores do Poder Judiciário. Este canal dialógico exerce também um papel importante na gestão e controle do trabalho, conforme as expectativas criadas pelo próprio CNJ. Uma lógica instrumental vai se desenhando, voltada para a eficiência controlada por dados 
estatísticos. O trabalho intelectual dos juízes e servidores vai sendo domesticado por variados métodos de controle, como é o caso do processômetro.

No entanto, entre o trabalho prescrito e o trabalho real existem fatores que dificultam a análise da produtividade e eficiência jurisdicional, uma vez que o processo não é um fim em si mesmo. Considerar o processo como um estoque que compromete o bom desempenho da função jurisdicional é negar valor a outra realidade igualmente importante: o processo tem um caráter instrumental e, como instrumento que é, deve servir ao fim último da jurisdição - fazer Justiça. Logo, posturas objetivantes de natureza gerencial que cosificam as relações intersubjetivas nele presentes podem implicar grave desrespeito à dignidade da pessoa humana e aos basilares princípios e garantias constitucionais. Com isto, em vez de assistirmos o acesso dos cidadãos à Justiça, podemos estar assistindo o surgimento de um modelo seletivo e excludente que nega o acesso oferecido.

Do que foi exposto, não se pretende negar ingenuamente a importância dos métodos de controle quantitativos. Pelo contrário, busca-se refletir sobre a necessidade de se analisar as questões apresentadas sob a ótica do imperativo moral que deve informar a gestão pública. Somente com esta perspectiva de agregar ao controle quantitativo abordagens éticas e morais da gestão gerencial é que se pode buscar um modelo de desempenho funcional eficiente. O drama humano não pode ser reduzido a mero dado estatístico e as informações que os consumidores oferecem ao subsistema judicial, através da ouvidoria, devem atender a outros fins que não somente a racionalidade instrumental focada na estabilização sistêmica e produtividade institucional. 


\section{REFERÊNCIAS}

BORGES, J. L. “A biblioteca de Babel”. In Fiç̧ões. Tradução de Carlos Nejar. São Paulo: Abril Cultural, 1972.

BRESSER PEREIRA, L. C. Da administração pública burocrática à gerencial. In Luiz Carlos Bresser Pereira e Peter Kevin Spink. Reforma do Estado e administração pública gerencial. (Orgs. e Tradução) Carolina Andrade. 7. Ed. - Rio de Janeiro: FGV, 2006.

. Construindo o Estado republicano: democracia e reforma da gestão pública. Tradução Maria Cristina Godoy. Rio de Janeiro: FGV, 2009.

CASTELLS, M. A sociedade em rede. Tradução de Roneide Venancio Majer. Atualização da 6. edição por Jussara Simões. São Paulo: Paz e Terra, 2011.

GIDDENS, A. As conseqüências da modernidade. Tradução de Raul Ficker. São Paulo: UNESP. 1991.

HABERMAS, J. Consciência moral e agir comunicativo. Tradução de Guido A. de Almeida. Rio de Janeiro: Tempo Brasileiro, 2003.

. Mudança Estrutural da Esfera Pública: investigações quanto a uma categoria da sociedade burguesa. Tradução de Flávio R. Kothe. Rio de Janeiro: Tempo Brasileiro, 2003.

KANT, I. Crítica da Razão Prática. Trad. Artur Morão. Lisboa : Edições 70, 2001.

LUHMANN, N. Introdução à teoria dos sistemas. Tradução de Ana Cristina Arantes Nasser. Petrópolis, RJ: Vozes, 2009.

STANISLAVSKI, C. A construção da personagem. 18. ed. Rio de Janeiro, Civilização Brasileira, 2009a. . A preparação do ator. Tradução de Pontes de Paula Lima. 26. ed. Rio de Janeiro: Editora Civilização Brasileira, 2009b.

SUPIOT, A. Homo Juridicus. Ensaio sobre a função antropológica do Direito. Tradução de Almeida Prado Galvão. São Paulo, 2007.

WEBER, M. A ética protestante e o "espírito" do capitalismo. Tradução de José Marcos Mariani de Macedo. Organização de Antonio Flávio Pierucci. São Paulo: Companhia das Letras, 2004.

http://portal2.trtrio.gov.br. Acessado em: 20.08.2012.

http://www.cnj.jus.br. Acessado em: 20.08.2012. 